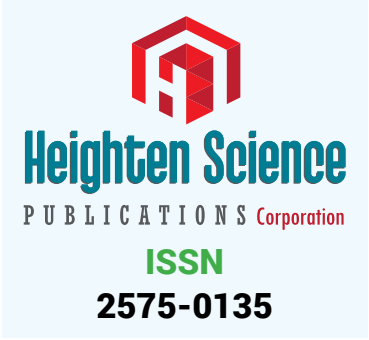

*Address for Correspondence: Magdalena Arasimowicz-Jelonek, Department of Plant Ecophysiology, Adam Mickiewicz University, Umultowska 89, 61-614 Poznan, Poland, Email: arasim@amu.edu.pl

Submitted: 09 January 2017 Approved: 27 February 2017 Published: 03 March 2017

Copyright: @ 2017 Arasimowicz-Jelonek M, et al. This is an open access article distributed under the Creative Commons Attribution License which permits unrestricted use, distribution, and reproduction in any medium, provided the original work is properly cited.

\title{
The Effects of Pharmacological \\ Carbonic Anhydrase Suppression on Defence Responses of Potato Leaves
}

\section{To Phytophthora Infestans}

\author{
Jolanta Floryszak-Wieczorek ${ }^{1}$ and Magdalena Arasimowicz- \\ Jelonek ${ }^{2 *}$ \\ 'Department of Plant Physiology, Poznan University of Life Sciences, Wolynska 35, 60-637 \\ Poznan, Poland \\ ${ }^{2}$ Department of Plant Ecophysiology, Adam Mickiewicz University, Umultowska 89, 61-614 \\ Poznan, Poland
}

\section{SUMMARY}

In this study we proposed carbonic anhydrase (CA) as an important element of basal resistance during the potato (Solanum tuberosum L.)-Phytophthora infestans interaction. We found a different $\beta$-CA expression pattern in incompatible vs. compatible systems correlated in time with CA enzyme activity. Resistant potato leaves supplied with dorzolamide (an inhibitor of carbonate CA activity) and challenged with the pathogen showed an elevated nitric oxide (NO) synthesis, which was the most evident during the early phase of NO burst (at 3 hpi) during hypersensitive response (HR). In vitro application of dorzolamide and effective inhibitors of NO synthesis confirmed the implication of CA activity in $\mathrm{NO}$ metabolism during potato defense. To clarify how suppression of CA carbonate activity translates into the complexity of NO-related responses leading to potato resistance or susceptibility to an oomycete pathogen we analysed expression of $N P R, P R 1$, and PAL.

Taken together, pharmacological damping of CA activity revealed a functional link between CA and NOdependent signaling in potato defense against $P$. infestans manifested by accelerated NO formation and a modified salicylic acid defense pathway. The dorzolamide-mediated effective responses for basal resistance also delayed symptoms of late blight in the susceptible potato cultivar, without overcoming HR formation in the resistant one.

\section{INTRODUCTION}

Carbonic anhydrases (CAs; EC 4.2.1.1) are ubiquitous metalloenzymes including zinc ligands that catalyze $\mathrm{CO}_{2}$ and $\mathrm{HCO}_{3}{ }^{-}$interconvertion. Plants have three types of CAs: $\alpha-, \beta$ - and $\gamma$-type CAs, which are expressed in various tissues and cell compartments [1]. In plants, CAs are mostly widespread in the cytoplasm, chloroplast stroma and in mitochondria [2]. Carbonic anhydrases play a key role in many physiological processes of plants, including photosynthesis, respiration, $\mathrm{CO}_{2}$ transport and electrolyte secretion among others [1,3]. They belong to the most efficiently acting enzymes over a very broad spectrum of acidity. It was found that CA participates in the regulation of chloroplast $\mathrm{pH}$ and protects stroma enzymes against denaturation during rapid and drastic changes under light conditions [4]. The most extensive study was devoted to $\beta$-CA involvement in the $\mathrm{CO}_{2}$ concentrating mechanism (CCM), which increases the concentration of this gas in close proximity to Rubisco and consequently decreases photorespiration [5].

How to cite this article: Floryszak-Wieczorek J, Arasimowicz-Jelonek M. The Effects of Pharmacological Carbonic Anhydrase Suppression on Defence Responses of Potato Leaves To Phytophthora Infestans. J Plant Sci Phytopathol. 2017; 1: 011-025. https://doi.org/10.29328/journal.jpsp.1001002 
It was well documented that CAs are highly expressed in leaf tissues and can represent up to $1-2 \%$ of soluble protein in a leaf [6]. Importantly, $\beta$-CAs are prevalently expressed CA genes in leaves [2] including $\beta C A 2$ and $\beta C A 3$ [7]. Apart from carbon dioxide fixation, it has been documented that $\beta$-CAs may contribute to plants' survival under abiotic stress conditions [8,9]. Unfortunately, due to a lack of in-depth studies the role of $\beta$-CA isoforms in plant adaptation to salts or osmotic stresses [10] and an engagement of this ubiquitous enzyme in plant defense against biotic factors are not well-defined either.

So far, it is known that in the immune response of plants to pathogens carbonic anhydrase plays a very important role, constituting a salicylic acid (SA) binding protein 3-SABP3 [11]. Interestingly, the used acetazolamide (a known CA inhibitor) inhibited the in vitro CA carbonate activity of this enzyme and in this way it showed that SA binding and CA enzymatic activity act independently. In turn, silencing of CA gene expression in tobacco leaves suppressed avr Pseudomonas syringae mediated hypersensitive response (HR) development. The SABP3 role has not been completely clarified to date, being defined as an antioxidant one.

It has been documented in Arabidopsis thaliana that the SABP3 regulatory protein undergoes a nitric oxide (NO)-mediated process of S-nitrosylation, resulting in strong suppression of both CA and SA binding activities [12]. This dual inhibition of AtSABP3 abolished the HR type immune plant response, which could contribute to a negative feedback loop modulating plant defense [12]. Interestingly, in the immune response of animal cells it may not be excluded that the above mechanism may be an element of the offensive strategy of the pathogen [13].

As we have documented in potato leaves, both CA and the StSABP2 isoform were S-nitrosylation targets upon infection with the oomycete Phytophthora infestans [14]. Additionally, it is worth noting that the attachment of NO to the cysteine residue of carbonic anhydrase was earlier found by [15] in healthy potato plants. Moreover, [16]. Showed that in sunflower under high temperature the $\beta$-CA activity was inhibited by a process of protein tyrosine $\left(\mathrm{Tyr}^{205}\right)$ nitration, another post-translational modification provoked by reactive nitrogen species. Proteomic approaches to identify tyrosine nitration of CA in Arabidopsis thaliana under physiological conditions and in potato under pathophysiological conditions were also discussed by [17] and [13,14] respectively.

Potato plastidic $C A$ was shown to have a distinct expression pattern in the compatible and the incompatible interactions after being challenged with $P$. infestans [18]. The $C A$ gene expression was strongly up-regulated at 6 to $24 \mathrm{~h}$ post inoculation (hpi) in the incompatible response and interestingly, in the same time-period the $C A$ gene was down-regulated in the compatible interaction. Previously, it was proposed that CA may participate in lipid biosynthesis [19], thus the strong inhibition of $C A$ transcript accumulation in the compatible system could have influenced suppression of genes connected with the jasmonate-dependent pathway or lipid metabolism. Moreover, using tobacco mutants with the silenced $C A$ gene, [18] revealed disease progress, indicating that suppression of $C A$ increases susceptibility to oomycete pathogens.

The involvement of CA in the primed mobilization for more potent defense responses to subsequent stress was earlier documented by our team using proteomic screening (2D) and protein identification with mass spectrometry tools [20]. It means that primed leaves of the susceptible potato cv. Bintje treated with the SAR inducers showed more potent defense responses to subsequent $P$. infestans stress [21], correlated with a periodical increase in CA protein expression [20]. Additionally, overlapping proteomic changes between priming agents and the NO-donor (S-nitrosoglutathione) supplied to leaves revealed another possible link between NO and CA that might lead to systemic acquired resistance. 
In this context, published data concerning the possibility of NO synthesis by CA revealed in mammals seemed to be interesting [22]. The discovery of the previously unknown activity of CA consisted in the involvement of this enzyme in the reduction of nitrites with the generation of NO, which in in vivo experiments resulted in an induced vasodilation in aortic rings. When applying inhibitors of CA carbonate activity, i.e. acetozolamide and dorzolamide, the above mentioned researchers obtained NO generation from nitrites, both in relation to purified anhydrase (CAI and CAII), and in extracts from different animal tissues. Unfortunately, within the last years no other research group has confirmed this new way of NO synthesis managed by CA.

To provide insight into the role of CA in plant defense responses which has not been completely clarified so far, we used a pharmacological approach in the form of dorzolamide (CA inhibitor) supplied into the potato leaf tissue. We analysed CA gene expression at transcript and protein activity levels, early after P. infestans challenge inoculation as well as NO generation and NO-mediated SA signaling defense in potato avr resistance and vr susceptibility to $P$. infestans.

\section{MATERIALS AND METHODS}

\section{Plant material}

Two potato lines, Solanum tuberosum L., 'Bintje' (susceptible) and 'Bzura'-resistant to $P$. infestans, were derived from in vitro tissue culture and kept in sterile soil in a phytochamber (16h/8 h: day/night; $180 \mu \mathrm{mol} \mathrm{m}^{-2} \mathrm{~s}^{-1}$ ) at $18 \pm 1^{\circ} \mathrm{C}$ and $60 \%$ relative humidity up to the stage of ten leaves.

\section{Pathogen culture and inoculation with $P$. infestans}

Phytophthora infestans (Mont.) de Bary (1.3.4.7.10.11., isolate MP946), virulent for 'Bintje' and avirulent for 'Bzura', was obtained from the Plant Breeding and Acclimatization Institute, Research Division at Młochów, Poland. Isolate MP946 triggered hypersensitive pointed cell death (HR) in the 'Bzura' genotype identified as TUNEL-positive [23]. Potato plants were inoculated by spraying leaves with $5 \mathrm{ml}$ of the oomycete zoospore suspension at a concentration of $1.0 \times 10^{5}$ per $1 \mathrm{ml}$ of water and then were kept overnight at $100 \%$ relative humidity and $18^{\circ} \mathrm{C}$ and afterwards they were transferred to a growth chamber.

\section{Assessment of disease index}

The area affected by disease symptoms was assessed on potato leaves 4-6 days after inoculation with $P$. infestans based on a scale from I to IV [24], which represented the percentage of leaf area covered by late blight symptoms (I=1 to $5 \%$; II=6 to $30 \%$; III=31 to 70\%; IV=71 to $100 \%$ ). Response of resistant 'Bzura' to avr P. infestans inoculation was expressed as the \% of leaves with HR lesions.

\section{Pharmacological inhibition of CA activity}

$250 \mu \mathrm{M}$ solution of dorzolamide was vacuum infiltrated to plant tissue with the use of a $4 \mathrm{l}$ vacuum jar by placing detached leaves in a solution of the inhibitor. After suction of the jar until -0.5 bar for $5 \mathrm{~min}$, the stop valve was released. Further, leaves were incubated by floating on the top of dorzolamide solution to minimize hypoxia. After 24h leaves were transferred to an infection chamber and subjected to $P$. infestans inoculation. In in vitro assays of NO generation, dorzolamide was added from a stock solution to a final concentration of $250 \mu \mathrm{M}$.

\section{Inhibition of NO-synthetizing enzymes}

To determine in vitro NO generation routes, specific inhibitors of reductive and oxidative NO sources were used, i.e. tungstate (TG), $\mathrm{N}_{\omega}$-Nitro-L-arginine methyl ester 
hydrochloride (L-NAME) and aminoguanidine (AG). To block NR activity, $0.1 \mathrm{mM}$ tungstate was used in in vitro assays. NOS-like routes of NO synthesis were affected by the addition of $5 \mathrm{mM}$ aminoguanidine (AG) with $5 \mathrm{mM}$ L-NAME.

\section{Measurement of nitric oxide emission}

Fluorimetric assay: The FL-NO fluorescence in extracts of potato leaves after inoculation was assayed spectrofluorimetrically using a selective nitric oxide sensor (CuFL) [25]. The copper-complex of FL (2-\{2-Chloro-6-hydroxy-5-[2-methylquinolin8-ylamino) methyl]-3-oxo-3H-xanthen-9-1\} benzoic acid) was prepared as $1 \mathrm{mM}$ water stock solution according to the manufacturer's instructions (Strem Chemicals). Leaf tissue (500 mg of fresh weight) was homogenized in $2 \mathrm{ml}$ of $10 \mathrm{mM}$ potassiumphosphate buffer ( $\mathrm{pH} 7.0$ ). The extract was centrifuged at $21,000 \times \mathrm{g}$ for $30 \mathrm{~min}$ at $4^{\circ} \mathrm{C}$. Then, $100 \mu \mathrm{l}$ of supernatant were immediately used for NO assay by adding CuFL to the final concentration of $2 \mu \mathrm{M}$. Fluorescence intensity was determined with the Fluorescence Spectrometer Perkin Elmer LS50B (UK) using $488 \mathrm{~nm}$ and $516 \mathrm{~nm}$ for excitation and emission, respectively. Each value was expressed as NO-FL fluorescence intensity $\left[\mathrm{Int} \times \mathrm{g}^{-1} \mathrm{FW}\right]$.

Chemiluminescence assay: The generation of NO was also measured by chemiluminescence assay as described by [22] with use of a Sievers ${ }^{\circledR}$ Nitric Oxide Analyzer NOA 280i (GE Analytical Instruments, USA). Leaf tissue (250 mg fresh weight) was homogenized in $2 \mathrm{ml}$ of $10 \mathrm{mM}$ potassium-phosphate buffer ( $\mathrm{pH} 7.2)$. The extract was centrifuged at $10,000 \times \mathrm{g}$ for $30 \mathrm{~min}$ at $4^{\circ} \mathrm{C}$. Then, $400 \mu \mathrm{l}$ of supernatant were immediately added to $8 \mathrm{~mL}$ of $10 \mathrm{mM}$ potassium-phosphate buffer (pH 7.2) with $300 \mu \mathrm{l}$ of an antifoam agent (30:1, v:v, Sigma-Aldrich) by injection to purge the vessel. The constant flow of nitrogen gas mixed the reaction mixture and released produced NO to the gas phase to be detected by the NO analyser. Successive injections of nitrite doses as well as NR and CA inhibitors were conducted without disturbing the assay conditions. Generation of NO was monitored in a real-time manner and was expressed as $\mathrm{mV}$.

Electrochemical assay: The generation of NO was monitored with a PGSTAT 30 universal electrochemical analyser (EcoChemie, Utrecht, and the Netherlands) according to the method proposed by [26]. NO generation in the leaf extract was monitored by differential pulse amperometry with an NO selective needle-type electrode prepared as described by [27]. The electrochemical measurement was performed with the use of differential pulse voltammetry.

\section{Carbonic anhydrase activity}

The activity of carbonic anhydrase was determined by a modified Wilbur-Anderson assay [28]. Leaf tissue ( $250 \mu \mathrm{g}$ of fresh weight) was ground in liquid nitrogen and homogenized with $2 \mathrm{ml}$ of $50 \mathrm{mM}$ HEPES buffer (pH 7.5), containing $10 \mathrm{mM}$ DTT, 0.5 mM EDTA and $0.1 \%$ Triton X-100 (v/v) and $10 \%$ glycerol $(\mathrm{v} / \mathrm{v})$. Homogenates were centrifuged at $15000 \times \mathrm{g}$ for $30 \mathrm{~min}$. Obtained supernatants were used directly for CA measurements. Enzymatic activity was determined following the time-dependent decrease in $\mathrm{pH}$ from 8.3 to 7.45 at 0 to $1^{\circ} \mathrm{C}$. Supernatant volume (25 $\left.\mu \mathrm{l}\right)$ was added to $2 \mathrm{ml}$ of $0.025 \mathrm{mM}$ Tris- $\mathrm{HCl}$ buffer (pH 8.3). Then, $1 \mathrm{ml}$ of $\mathrm{CO}_{2}$-saturated distilled $\mathrm{H}_{2} \mathrm{O}$ was added to the assay (approx. $76 \mathrm{mM}, 0-1^{\circ} \mathrm{C}$ ). The reaction mixture was stirred constantly in a 3-ml cuvette and the decrease of $\mathrm{pH}$ was monitored with a $\mathrm{pH}$ microelectrode (HI108312, Hanna instruments). The units (U) of enzyme activity were calculated according to the equation $\mathrm{U}=10 \times\left(\mathrm{T}-\mathrm{T}_{0}\right) / \mathrm{T}_{0}$, where $\mathrm{T}$ and $\mathrm{T}_{0}$ represent the time required to reduce $\mathrm{pH}$ from 8.3 to 7.45 with and without the enzymatic extract, respectively. Enzyme activity was expressed as U×mg-1 protein. Protein content was determined using the Bradford reagent. 


\section{Gene expression measurements}

The RNA was isolated from $150 \mathrm{mg}$ of frozen leaf tissue using TriReagent ${ }^{\circledR}$ (Sigma) according to the method of [29]. The obtained RNA was purified with the use of a Deoxyribonuclease I Kit (Sigma). For the reverse transcription $1 \mu$ l of RNA from every experimental variant was processed with a RevertAid ${ }^{\mathrm{TM}}$ Reverse Transcriptase Kit (Thermo Scientific) according to the manufacturer's instructions. Real-time PCR was performed on a Rotor Gene 6000 Thermocycler (Corbett Life Sciences). The reaction mixture contained $0.1 \mu \mathrm{M}$ of each primer, $1 \mu \mathrm{l}$ of $5 \times$ diluted cDNA, $10 \mu \mathrm{l}$ of the Power SYBR $^{\circledR}$ Green PCR Master mix (Applied Biosystems) and DEPC-treated water to the total volume of $20 \mu \mathrm{l}$. The real-time PCR reaction conditions included an initial 5-min denaturation at $95^{\circ} \mathrm{C}$, followed by 55 cycles consisting of $10 \mathrm{~s}$ at $95^{\circ} \mathrm{C}, 20 \mathrm{~s}$ at $53^{\circ} \mathrm{C}$ and $30 \mathrm{~s}$ at $72^{\circ} \mathrm{C}$. Primers for genes (CA, PR1, NPR1, and PAL) transcript accumulation are presented in the Table 1 . The data were normalized to the reference genes encoding the elongation factor and 18S rRNA. All used primers were designed using PrimerBLAST [30]. The $C_{t}$ values were determined with the use of a Real-time PCR Miner [31] and the relative gene expression was calculated with the use of efficiency corrected calculation models presented by [32].

\section{The influence of dorzolamide on $P_{\text {. infestans }}$}

To test the effect of dorzolamide on P. infestans mycelium growth, a standard peaagar medium was prepared with four wells excised from the medium and then filled with the following DA concentrations: $25 \mu \mathrm{M}, 250 \mu \mathrm{M}$ and 2.5mM. After 2-week-growth under standard conditions, the area of $P$. infestans mycelium was photographed and assessed using the ImageJ software.

\section{Statistical analysis}

All results were based on at least three independent experiments, each with at least three biological replicates. Analysis of variance was conducted and the least significant differences (LSD) between means were determined using Tukey's test at the significance level $P=0.05$. The SigmaPlot 11.0 software (Systat) was used to perform statistical tests.

\section{RESULTS}

\section{Involvement of CA in potato response to the oomycete pathogen}

In line with previous reports $[33,34]$ our results suggest that the following hours of the first day after inoculation are critical for HR execution or its attenuation in potato- $P$. infestans interaction. Because the $\mathrm{CA}$ role in resistance has not been completely clarified so far, we analysed CA gene expression at transcript and protein activity levels early after $P$. infestans challenge inoculation.

The avirulentrace of the pathogen did not elicitincreased $C A$ transcript accumulation

Table 1: Primers used in real-time PCR reactions.

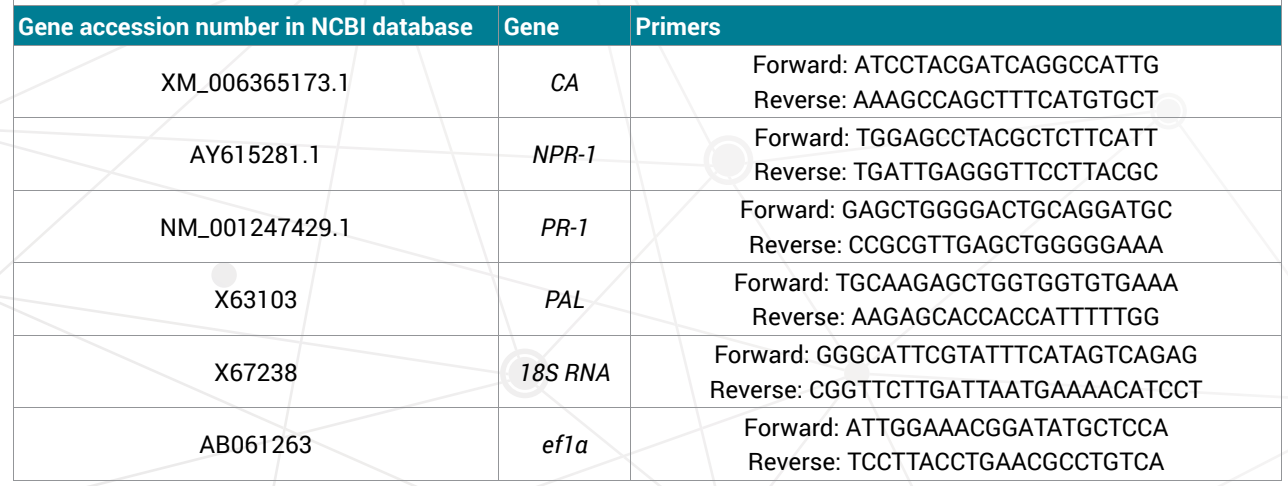


until 6hpi. Marked up-regulation of this gene (above 3-fold increase) was noted at $6 \mathrm{hpi}$, then in the successive hours the $C A$ transcript level slowly declined. However, at $48 \mathrm{hpi}$ it was consequently higher than in uninfected potato leaves (Figure 1a). In contrast to the resistant response, in the vr P. infestans-potato interaction the $C A$ gene expression systematically increased from 1 to $6 \mathrm{hpi}$ and in the following hours it was significantly suppressed (Figure 1a). It is noteworthy that at 6hpi the most enhanced CA mRNA level was similar in both genotypes (Figure 1a). Dorzolamide application prior to inoculation strongly inhibited CA (up to approx.80\%) at the transcript level in both potato genotypes in comparison to the P. infestans inoculated plants (Figure 1b,c).

CA enzyme activity was constitutively almost two-fold lower in the resistant genotype than the susceptible one (Figure 1d). Potato leaves challenge-inoculated with the avirulent pathogen showed an increase in CA activity from 6 to $24 \mathrm{hpi}$, followed by a decrease at $48 \mathrm{hpi}$. In turn, vr P. infestans provoked an enhanced CA activity at
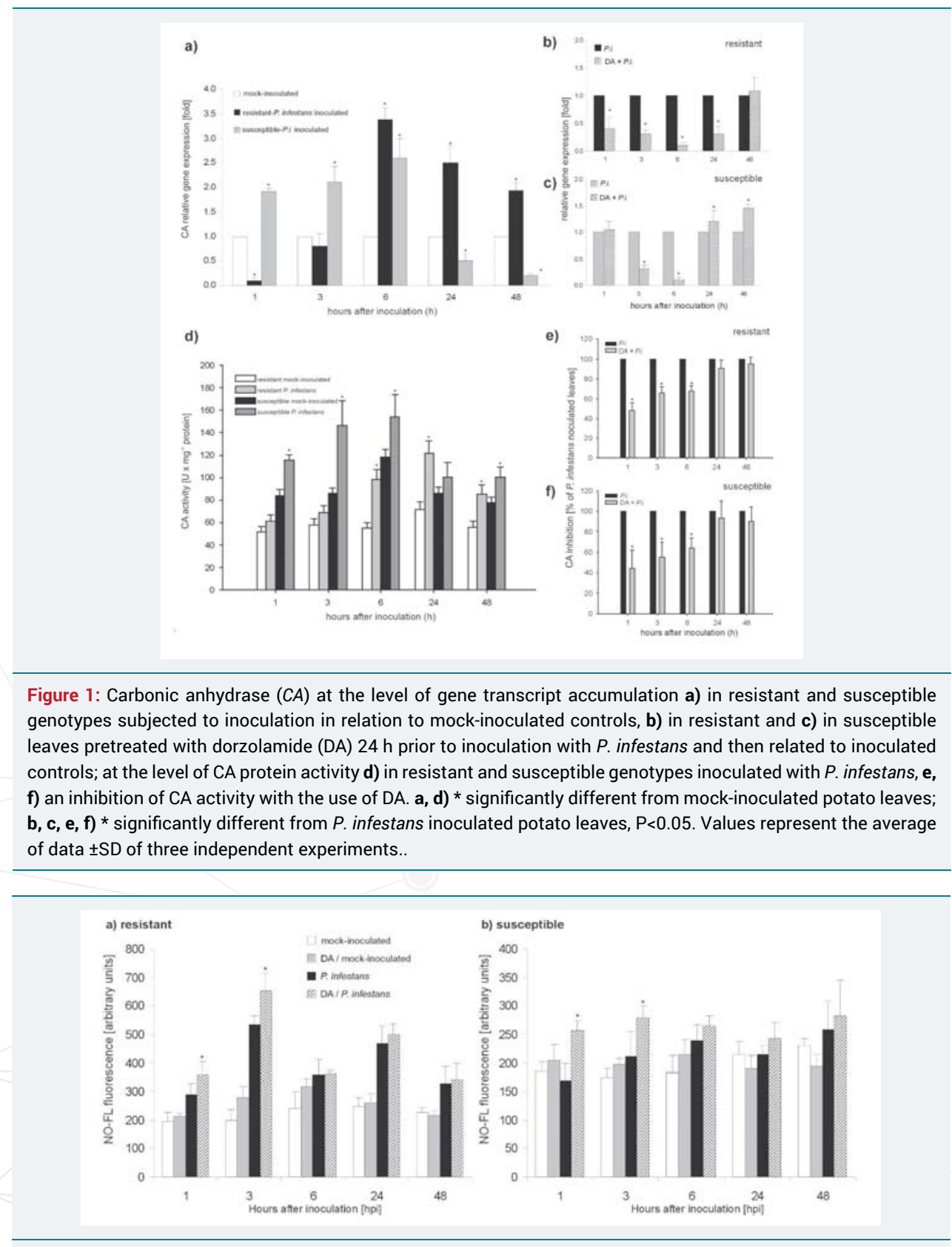

Figure 2: Nitric oxide generation in potato leaves of a) resistant and b) susceptible genotype treated with dorzolamide (DA) and/or challenge inoculated (P.i.). * Significantly different from inoculated potato leaves, $P<0.05$. Values represent the average of data $\pm S D$ of at least three independent experiments. 
1-24hpi; however, it was subsequently decreased after 6hpi (Figure 1d). Pretreatment with DA prior to inoculation effectively inhibited carbonate CA activity within the first $6 \mathrm{hpi}$ in both potato cultivars (Figure 1e,f).

\section{Dorzolamide accelerates NO signal generation in potato}

A biphasic NO formation was recently found by our team in avr P. infestans inoculated resistant potato [35]. Applied dorzolamide as a CA inhibitor only slightly and temporary increased NO production (until $6 \mathrm{~h}$ ) in healthy leaf tissue (Figure 2). In turn, resistant potato leaves supplied with the CA inhibitor and then challenged with the pathogen showed an elevated NO synthesis with the same intensity and kinetics of its emission as in avr P. infestans/resistant potato leaves (Figure 2a). DA pretreatment of susceptible potato revealed also significant changes in the NO status during the first 3 hpi (Figure 2b).

\section{Impact of dorzolamide and effective inhibitors of NO synthesis on the early NO burst during HR response}

Since we found that suppression of carbonate CA activity by DA significantly accelerated NO formation during the resistant response we tried to answer the question whether and if so, $\mathrm{CA}$ is implicated in NO metabolism in potato response to avr P. infestans. To this aim we measured NO production at 3hpi during HR response after application of different inhibitors of NO synthesis. First NO production was analysed in vitro using an NO-dependent fluorochrome $\mathrm{Cu}-\mathrm{FL}$ in the presence of the following inhibitors: dorzolamide (DA), tungstate (TG) and aminoguanidine (AG) with L-NAME used either separately or jointly (Figure 3). Dorzolamide enhanced NO generation in both mock-inoculated and avr P. infestans inoculated leaf extracts by ca. $7 \%$ and $16 \%$, respectively. In turn, NO-FL fluorescence (in avr inoculated leaves) was strongly suppressed by a combination of DA and tungstate (52\%), as well as less strongly by DA and AG with L-NAME (38\%) when compared with avr inoculated leaves without an inhibitor. To further determine whether nitrite could play an essential role in NO biosynthesis, the avr inoculated potato leaf extract (at $3 \mathrm{hpi}$ ) containing a specific inhibitor was supplied with $100 \mu \mathrm{M} \mathrm{NO}_{2}^{-}$(Figure 3). Supplementation of the inoculated leaf extract with DA and exogenous nitrite showed an enhanced NO production (25\%). Surprisingly, NO-dependent fluorescence was the most intensive when the analysed solution, in addition to DA and nitrite, contained also TG, an inhibitor of nitrate reductase (an increase by ca. 36\% in comparison to avr inoculated leaves).

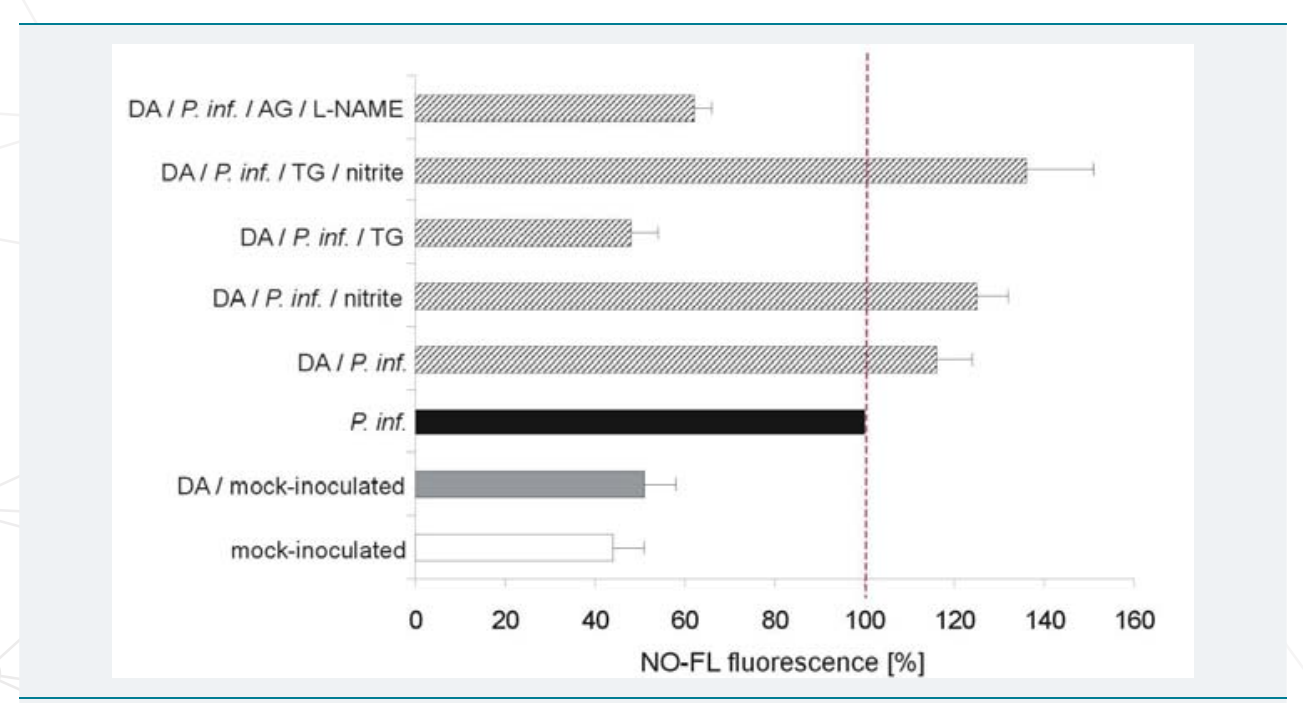

Figure 3: Nitric oxide generation in mock-inoculated (control) and inoculated resistant potato leaves (at 3 hpi) analyzed in vitro with the following inhibitors: $0.1 \mathrm{mM} \mathrm{Na}_{2} \mathrm{WO}_{4}(\mathrm{TG}), 5 \mathrm{mM} \mathrm{L-NAME}$ with $5 \mathrm{mM} \mathrm{AG}$ or $250 \mu \mathrm{M} \mathrm{DA}$, used separately or in combination; $\mathrm{NO}$ emission was also monitored in medium supplied with $100 \mu \mathrm{M} \mathrm{NO}_{2}^{-}$plus TG or deprived of it. Values represent the average of data \pm SD of at least three independent experiments. 
To further verify if the observed suppression of the CA carbonate activity pattern correlated in time with the enhanced generation of NO (at 3hpi) in the host reply to the pathogen we applied additional supersensitive NO detection tools (NO-specific microelectrode and chemiluminescence analyser - Sievers Nitric Oxide Analyzer NOA

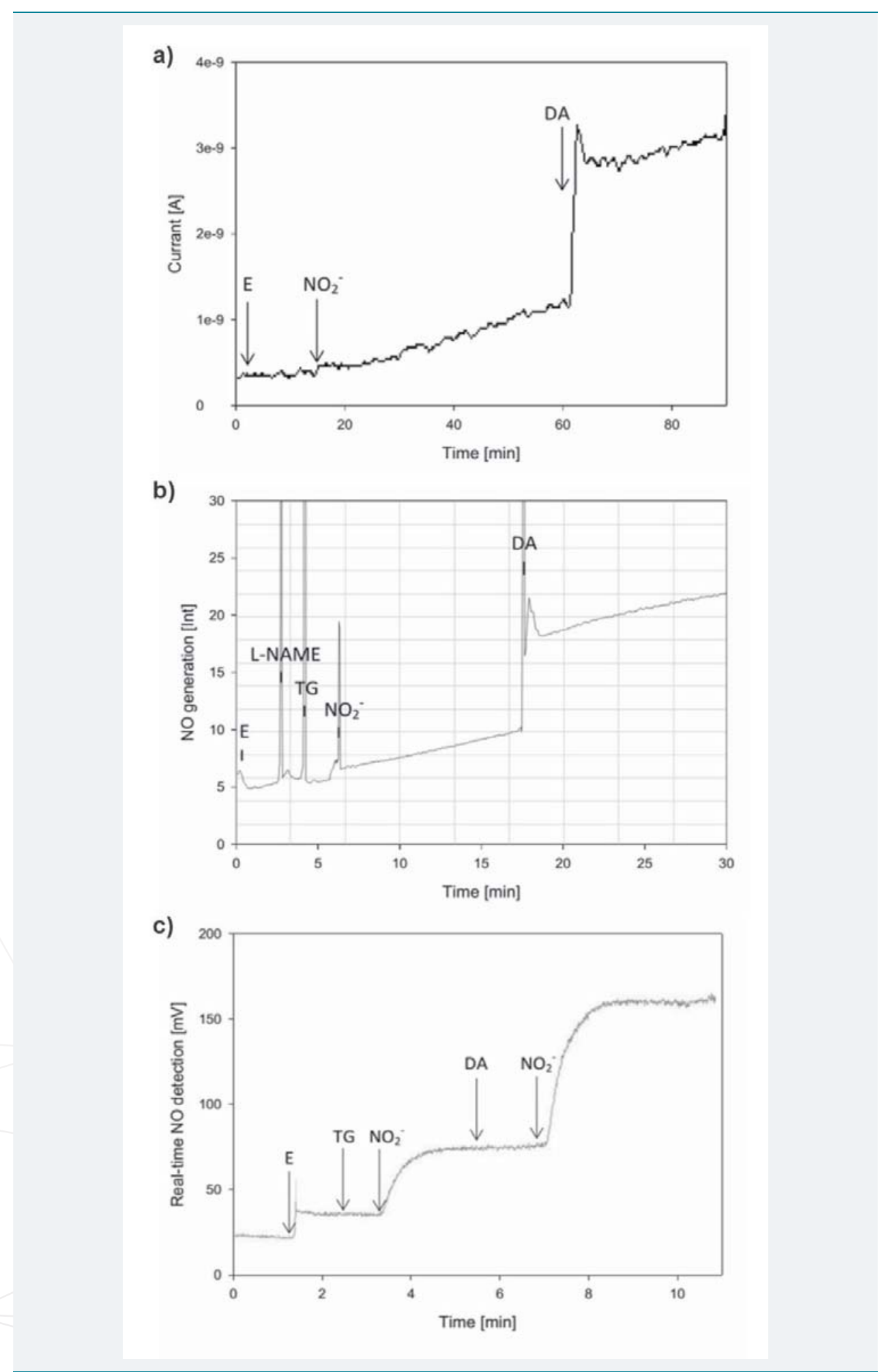

Figure 4: Nitric oxide generation in extract of avr inoculated potato (Solanum tuberosum L.) leaves at $3 \mathrm{hpi}$. a) NO assayed with the use of the electrochemical approach and NO-selective microelectrode; b) NO determined fluorimetrically with the use of fluorochrome CuFL;c) NO determined by chemiluminescence method with Sievers Nitric Oxide Analyzer NOA 280i. NO detection was performed after addition of plant extract (E) and following reagents: $100 \mu \mathrm{M} \mathrm{NO}_{2}{ }^{-}, 250 \mu \mathrm{M}$ dorzolamide (DA), $0.1 \mathrm{mM}$ tungstate (TG) and $5 \mathrm{mM} \mathrm{N}$-Nitro-L-arginine methyl ester hydrochloride (L-NAME). At least three independent experiments were conducted; arrows indicate the point of adding the reagent. 
280i), which were used by [22], the authors of a pioneering report on NO generation managed by CA in mammals. Considering the structural similarity between bicarbonate and nitrite, the above-mentioned authors documented that CA used nitrite as a substrate to produce NO under normoxic conditions in response to the inhibition of carbonate CA activity by acetazolamide or dorzolamide.

Obtained data revealed that the sequential treatment of potato leaf extracts with NR and/or NOS-like activity inhibitors (TG and L-NAME) followed by nitrite (100 $\mu \mathrm{M}$ $\mathrm{KNO}_{2}$ ) resulted in a relatively low level of $\mathrm{NO}$ generation. In turn, when dorzolamide $(250 \mu \mathrm{M}$ DA) was added to the reaction mixture, a much more intensive NO production was observed in the extract obtained from avr P. infestans-inoculated leaves (Figure $4 a-c)$.

Interestingly, gas-phase NO emission was higher in the leaf extract of avr resistant (Figure Suppl. 1a) rather than vr susceptible (Figure Suppl. 1b) plants in the presence of tungstate, nitrite and DA, respectively. No signal was observed when the solution contained only increased levels of nitrite (Figure Suppl. 1c).

\section{The effects of pharmacological CA suppression on SA-dependent defence}

Quantitative real-time RT-PCR was performed to analyse expression levels of NPR1, $P R-1$, and $P A L$ genes upon inoculation, in order to better clarify how CA suppression affected the NO mediated SA-signalling defence pathway in potato leaves.

Early up-regulation of NPR1 tuned with the PR1 gene expression was found in

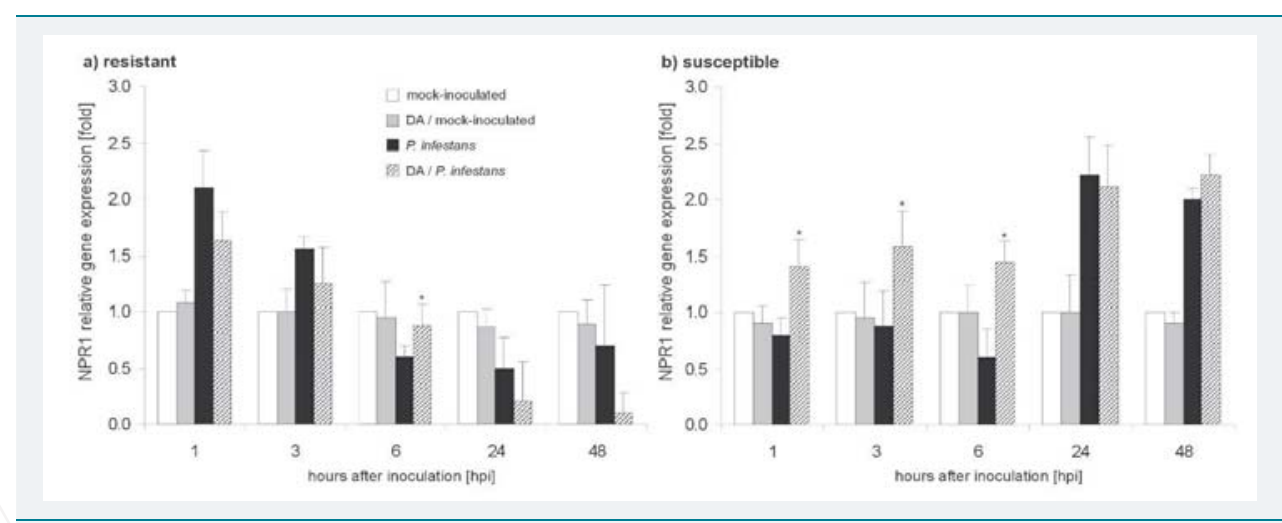

Figure 5: Accumulation of non-expresser of PR1 (NPR1) gene transcript a) in resistant and b) susceptible genotypes subjected to inoculation or pre-treated with dorzolamide (DA) $24 \mathrm{~h}$ prior to inoculation with $\mathrm{P}$. infestans in relation to mock-inoculated controls. *Significantly different from inoculated potato leaves, $\mathrm{P}<0.05$. Values represent the average of data $\pm S D$ of three independent experiments.

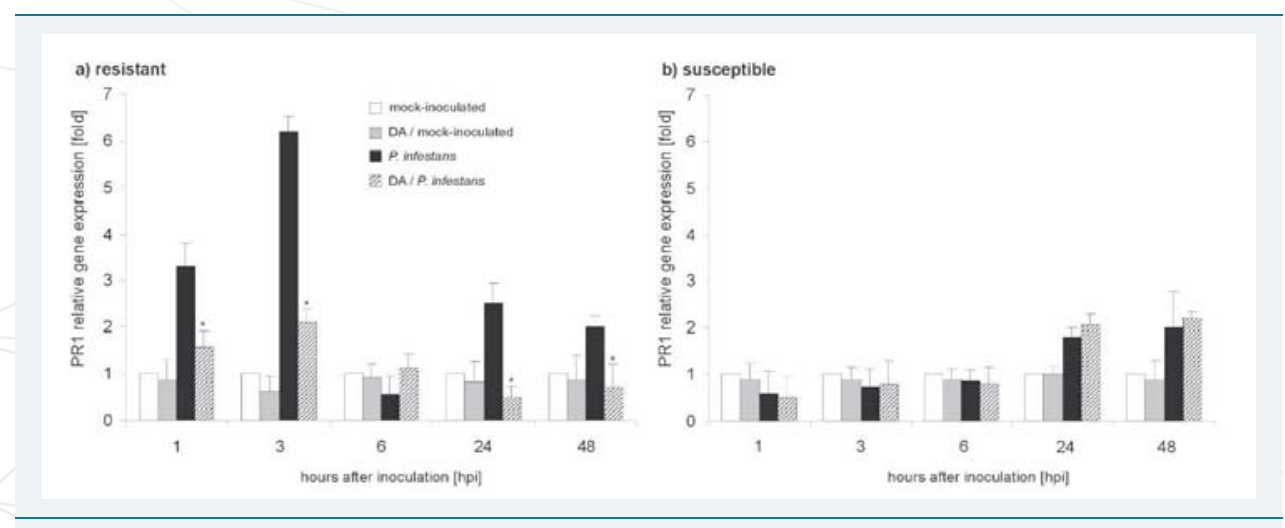

Figure 6: Accumulation of pathogenesis-related 1 (PR1) at the gene transcript level a) in resistant and b) susceptible genotypes subjected to inoculation or pre-treated with dorzolamide (DA) $24 \mathrm{~h}$ prior to inoculation with $\mathrm{P}$. infestans in relation to mock-inoculated controls. * Significantly different from inoculated potato leaves, $\mathrm{P}<0.05$. Values represent the average of data $\pm S D$ of three independent experiments. 
resistant potato (Figure 5,6), while an effective CA inhibitor treatment visibly blocked NPR1 and PR1 mRNA transcript accumulation in the following hours after avr pathogen inoculation, except for $6 \mathrm{hpi}$, when a temporary increase of these parameters was observed. In contrast to the resistant response, in the susceptible one a late over expression (24-48hpi) of $N P R$ and $P R 1$ gene expression was noted. Moreover, DA supply enhanced the NPR1 mRNA level at 1 to $6 \mathrm{hpi}$, but without affecting PR1 gene expression.

In both types of interaction, $P A L$ expression increased in the following time points after inoculation (Figure 7). The application of the CA inhibitor did not modify mRNA coding for PAL in the resistant response of potato to avr P. infestans (Figure 7a). It is worth stressing that in the susceptible potato, sequentially treated with dorzolamide and then challenge-inoculated with vr P. infestans, a drastically up-regulated $P A L$ expression (even 7-fold) was recorded at 1-48hpi as compared to infected DA nontreated leaves (Figure $7 \mathrm{~b}$ ).

\section{Inhibition of CA activity and potato resistance to $P$. infestans}

No significant differences in disease progress were observed when potato leaves were infiltrated with DA and then inoculated with the avr pathogen as opposed to the avr P. infestans-potato system without a CA inhibitor (Figure 8b). The rate of

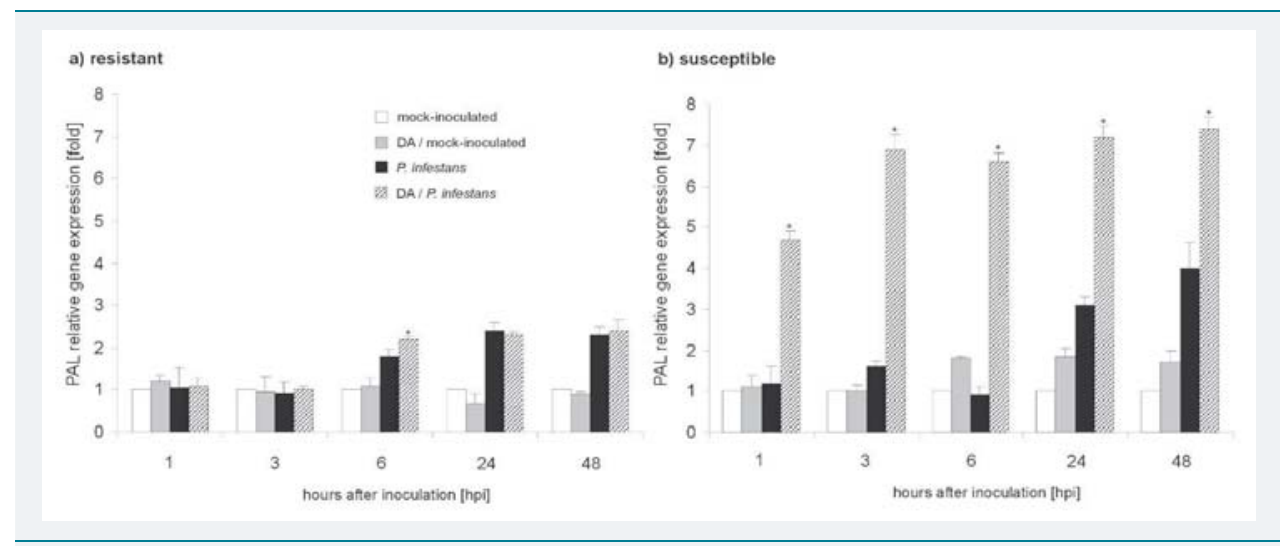

Figure 7: Accumulation of phenylalanine ammonia-lyase (PAL) gene transcript a) in resistant and b) susceptible genotypes subjected to inoculation or pre-treated with dorzolamide (DA) $24 \mathrm{~h}$ prior to inoculation with $\mathrm{P}$. infestans in relation to mock-inoculated controls. *Significantly different from inoculated potato leaves, $\mathrm{P}<0.05$. Values represent the average of data \pm SD of three independent experiments.

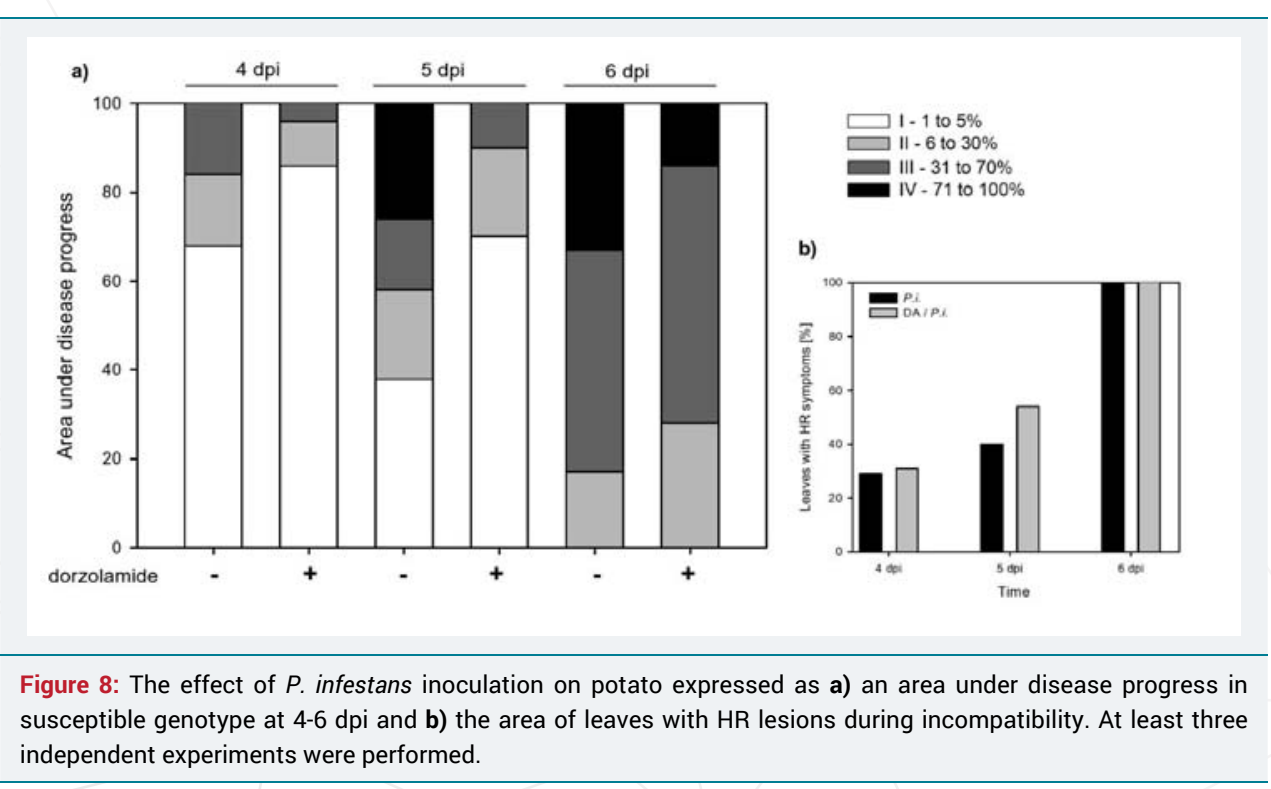


growth and the number of late blight HR-like spots were considerably similar in both treatments, so CA suppression did not modify disease development in the incompatible interaction.

In turn, experiments revealed a slow rate of late blight symptom development when leaves of the susceptible potato were first supplied with the CA inhibitor and then inoculated (Figure 8a). This means that pre-exposure of susceptible potato to DA and a subsequent challenge inoculation caused disease limitation, resulting in approx. 30 and $50 \%$ reduction of disease spots at the $4^{\text {th }}$ and $5^{\text {th }}$ day after $P$. infestans treatment, respectively. Less pronounced quantitative differences between these experimental combinations were found at the later days upon oomycete invasion of the susceptible potato leaf tissue.

Additionally, we observed that different concentrations of dorzolamide did not affect the mycelium growth of $P$. infestans on the solidified nutrient medium (Suppl. Figure 2).

\section{DISCUSSION}

Although most research on the ubiquitous enzyme CA has highlighted its significant role in $\mathrm{CO}_{2}$ fixation, it is becoming increasingly likely that $\mathrm{CA}$ isoforms also have diverse unexplored functions in plant cells. To investigate the role of CA in plant adjustment to biotic stress we adopted a pharmacological approach using dorzolamide as an inhibitor of carbonate CA activity. At the beginning we found various profiles of $C A$ gene expression differentiating compatible and incompatible response of potato leaves to $P$. infestans, in line with the results of [18]. Obtained data revealed a two-fold higher level of constitutive CA activity and an enhanced level of $C A$ expression from 1 to $6 \mathrm{hpi}$ in the compatible interaction to the pathogen. In the following hpi mRNA for the $C A$ transcript drastically decreased, in contrast to the HR resistance response, where $C A$ gene expression peaked at $6 \mathrm{hpi}$ to decrease in the following hours (24-72 hpi). In turn, studies of [18] showed a strong inhibition of $C A$ at $24-48 \mathrm{hpi}$ and its recovery at $72 \mathrm{hpi}$ in the incompatible interaction to $P$. infestans.

It should be noted that there are still conflicting data with reference to the observed up- or down-regulation of CA and its involvement in plant response to the pathogen. It is dominated by reports on CA gene repression, e.g. in Arabidopsis in the incompatible response to Alternaria brassicicola or after treatment with SA, MJ or ethylene [36], in tomato plants supplied with a fungal toxin fusicoccin [37] or in a susceptible cultivar of grapevine infected with Plasmopara viticola [38]. The observed discrepancy in the clarification of gene expression with functional activities of CA is frequently ascribed to different plant-pathogen systems, depending on the biology of the pathogen, time after inoculation, duration of other stress treatments, the type of resistance (R-resistance, basal resistance or SAR resistance), or the applied molecular technique of gene expression analysis.

Nitric oxide is an important signalling molecule engaged in various plant responses to developmental and stress stimuli [39]. As we recently found, the endogenous NO level in potato leaves displayed a time-dependent increase during HR response. The NO emission was biphasic in character, with an early strong rise at $3 \mathrm{hpi}$ and a weaker one at $24 \mathrm{hpi}$. The first transient phase of NO overproduction seems to be important in the determination of the resistant response to the avr pathogen [35]. A similar pattern of NO overproduction with the first higher peak of NO recorded at 1 hpi and the second weaker at 6-8 hpi was observed in a soybean cell suspension treated with avr P. syringae [40]. A biphasic NO generation was also reported in wheat and Arabidopsis $[41,42]$ under osmotic stress. According to the authors, the early stress-induced NO 
generation might play a significant role in the process of plant acclimation to stress conditions.

In the present study we found that suppression of carbonate CA activity in potato leaves supplied with dorzolamid accelerates NO generation early after avr $P$. infestans inoculation, while it is less pronounced during the potato-vr P. infestans interaction. This result presents a new, functional link between CA and NO in potato leaf resistance to $P$. infestans. As we earlier indicated, NO might dually adjust CA activity either by a reversible attachment of $\mathrm{NO}$ to the cysteine residue of $\mathrm{CA}$ or by an irreversible tyrosine nitration of CA protein $[13,14]$.

Although NR is the most considerable pathway of NO generation in plants, there is a growing body of evidence that nitrites might be converted into $\mathrm{NO}$ also via the NR-independent route. The possibility of NO synthesis from nitrite managed by CA in the presence of dorzolamide was documented before by [22] in mammals. Notably, it is presented in our study that the avr inoculated potato leaf extract (at 3hpi) supplemented in vitro with dorzolamide and $50 \mu \mathrm{M}$ nitrite emitted over $25 \%$ more NO than the avr infected one. However, the most intensive NO-dependent fluorescence, greater by ca. $36 \%$ in comparison to avr inoculated leaves, was recorded in the extract containing dorzolamide and nitrite and TG (Figure 3).

Another experimental approach using supersensitive electrochemical, fluorometric and chemiluminescence techniques showed that the potato extract from the resistant genotype (3hpi) treated with tungstate in the presence of nitrite restored NO emission, but after an addition of dorzolamide NO production significantly increased. Moreover, the potato extract derived from the resistant genotype (3hpi) showed a much more intensive NO emission than that from the susceptible one (3hpi) (Figure Suppl. S1). Obtained data, however, require further detailed studies providing more conclusive evidence for CA-dependent or independent NO production from nitrite in potato. It should be noted that we approach this finding with great caution, the more so because Arabidopsis recombinant protein at $\beta C A 1$, having CA activity, was unable to convert nitrite to NO [43]; however, the cited poster presentation did not show the presence of any CA inhibitor in the tested buffer with recombinant protein.

The current lack of irrefutable data on CA ability to promote NO biosynthesis does not exclude a functional link between NO and CA in potato leaf resistance to Phytophthora infestans. It was documented that silencing of CA gene expression in Nicotiana benthamiana suppressed avr Pseudomonas syringae mediated HR in leaves [11] and increased susceptibility to P. infestans [18]. Based on this statement we examined how dorzolamide as an effective inhibitor of carbonate CA activity, but not SA-binding activity [11], affected NO-related defence responses to $P$. infestans. This set of experiments revealed that the used inhibitor of CA activity reduced the expression of host defence genes, i.e. NPR1, PR1 and PAL, at all time-points upon inoculation without overcoming HR formation during the incompatible interaction. In turn, in the susceptible potato leaves the suppression of CA activity effectively delayed symptoms of late blight disease. The limitation of cell death observed after inoculation with vr $P$. infestans correlated with an early and slight up-regulation of NPR1 gene expression and with an extending enrichment of mRNA coding for PAL. In general, the obtained data suggest that a decline of CA carbonate activity modified the SA-signalling pathway, thus facilitating effective basal resistance responses to the oomycete pathogen.

The results of this paper and other published data may be summarised to argue that the major role for cytosolic CA remains to be clarified. Considering the fact that although CA was mainly located in the chloroplast (87\% of total cellular activity), a significant activity (13\%) was found in the cytosol [44]. According to the abovementioned authors, if we take into account the volume of each compartment, 
estimated subcellular volumes occupied by the stroma and cytosol representing $9.5 \%$ and $3.4 \%$ of the mesophyll cell capacity, respectively [45], the CA concentration in the chloroplast would be about twofold higher than in the cytosol. Although both potato CA isoenzymes exhibited immunological similarity, cytosolic isoforms were differentially regulated by light and it might suggest another physiological role for the cytosolic CA than in photosynthesis.

Summing up, presented results have revealed non photosynthetic functions of CA isoforms in plant adjustment to biotic stress. The potato resistant response was accompanied by a relatively late and transient induction of CA activity, whereas the susceptible one revealed a significantly increased enzyme activity starting from the $1^{\text {sth }}$ of disease progress. However, the early suppression of CA carbonate activity by dorzolamide accelerated NO emission and NO-mediated defense responses, including induction of SA-signaling pathway. Thus, the sequence of events facilitating effective responses for basal resistance to vr $P$. infestans was governed by an enhanced NO status in potato leaves. What is more, in vitro application of DA and effective inhibitors of NO synthesis confirmed the implication of CA in NO synthesis during potato defense responses. Although $\mathrm{NO}$ emission in the presence of dorzolamide was independently monitored in potato using an NO-specific microelectrode, a fluorescent probe coppercomplex and an NO-chemiluminescence detector, there is a risk that dorzolamide has also affected other, unknown NO synthesis pathways. Therefore, in the future an integrated genetic and pharmacological approach will be needed to investigate the role of CA activities, particularly those tuned with NO-mediated resistance in potato.

\section{ACKNOWLEDGEMENTS}

The authors are greatly thankful to Dr D. Abramowski for his help in nitric oxide determination.

This work was supported by a grant of the National Science Centre-project no. NCN 2011/01/B/NZ9/00243.

\section{(Supplementry Metearials)}

\section{REFERENCES}

1. Moroney JV, Bartlett SG, Samuelsson G. Carbonic anhydrases in plants and algae. Plant Cell Environ. 2001; 24: 141-153. Ref.: https://goo.gl/YTHFVd

2. DiMario RJ, Quebedeaux JC, Longstreth DJ, Dassanayake M, Hartman MM, et al. The cytoplasmic carbonic anhydrases $\beta C A 2$ and $\beta C A 4$ are required for optimal plant growth at low $\mathrm{CO}_{2}$. Plant Physiol. 2016; 171: 280-293. Ref.: https://goo.gl/nOYqS2

3. Badger MR, Price GD. The Role of Carbonic anhydrase in photosynthesis. Annu Rev Plant Physiol Plant Mol Biol. 1994; 45: 369-392. Ref.: https://goo.gl/DxgDJ7

4. Reed ML, Graham D. Carbonic anhydrase in plants: distribution, properties and possible physiological roles, In: Progress in phytochemistry, Pergamon Press, Oxford, Reinhold L, Harborne JB, Swaquin T. 1981; 7: 47-94.

5. Badger $\mathrm{M}$. The roles of carbonic anhydrases in photosynthetic $\mathrm{CO}_{2}$ concentrating mechanisms. Photosynth Res. 2003; 77: 83-94. Ref.: https://goo.gl/ee26MF

6. Tobin AJ. Carbonic anhydrase from parsley leaves. J Biol Chem. 1970; 245: 2656-2666. Ref.: https://goo.gl/G1h6WD

7. Fabre N, Reiter IM, Becuwe-Linka N, Genty B, Rumeau D. Characterization and expression analysis of genes encoding alpha and beta carbonic anhydrases in Arabidopsis. Plant Cell Environ. 2007; 30 : 617-629. Ref.: https://goo.gl/UQDkoH

8. Kaul T, Reddy PS, Mahanty S, Thirulogachandar V, Reddy RA, et al. Biochemical and molecular characterization of stress-induced $\beta$-carbonic anhydrase from a $\mathrm{C}_{(4)}$ plant, Pennisetum glaucum. $J$ Plant Physiol. 2011; 168: 601-610. Ref.: https://goo.gl/99FF4U 
9. Pal A, Borthakur D. Tissue-specific differential expression of two $\beta$-carbonic anhydrases in Leucaena leucocephala under abiotic stress conditions. J Appl Biotechnol. 2014; 2: 43. Ref.: https://goo.gl/MIOgVx

10. Yu S, Zhang X, Guan Q, Takano T, Liu S. Expression of a carbonic anhydrase gene is induced by environmental stresses in Rice (Oryza sativa L.). Biotechnol Lett. 2007; 29: 89-94. Ref.: https://goo.gl/XyFgQz

11. Slaymaker DH, Navarre DA, Clark D, Del Pozo O, Martin GB, et al. The tobacco salicylic acid-binding protein 3 (SABP3) is the chloroplast carbonic anhydrase, which exhibits antioxidant activity and plays a role in the hypersensitive defense response. Proc Natl Acad Sci U S A. 2002; 99: 11640 11645. Ref.: https://goo.gl/Jvy8W1

12. Wang YQ, Feechan A, Yun BW, Shafiei R, Hofmann A. S-Nitrosylation of AtSABP3 antagonizes the expression of plant immunity. J Biol Chem. 2009; 284: 2131-2137. Ref.: https://goo.gl/mzYzRF

13. Arasimowicz-Jelonek M, Floryszak-Wieczorek J, Izbiańska K, Gzyl J, Jelonek T. Implication of peroxynitrite in defence responses of potato to Phytophthora infestans. Plant Pathol. 2015; 65: 754766. Ref.: https://goo.gl/c13iic

14. Abramowski D, Arasimowicz-Jelonek M, Izbianska K, Billert $H$, Floryszak-Wieczorek J. Nitric oxide modulates redox-mediated defense in potato challenged with Phytophthora infestans. Eur J Plant Pathol. 2015; 143: 237-260. Ref.: https://goo.gl/uU1LN6

15. Kato $\mathrm{H}$, Takemoto D, Kawakita K. Proteomic analysis of S-nitrosylated proteins in potato plant. Physiol Plant. 2013; 148: 371-386. Ref.: https://goo.gl/J77aZz

16. Chaki M, Valderrama R, Fernández-Ocaña AM, Carreras A, Gómez-Rodríguez MV, et al. High temperature triggers the metabolism of S-nitrosothiols in sunflower mediating a process of nitrosative stress which provokes the inhibition of ferredoxin-NADP reductase by tyrosine nitration. Plant Cell Environ. 2011; 34: 1803-1818. Ref.: https://goo.gl/VHju6f

17. Lozano-Juste J, Colom-Moreno R, Leon J. In vivo protein tyrosine nitration in Arabidopsis thaliana. J Exp Bot. 2011; 62: 3501-3517. Ref.: https://goo.gl/mQQ1zj

18. Restrepo S, Myers KL, del Pozo O, Martin GB, Hart AL, et al. Gene profiling of a compatible interaction between Phytophthora infestans and Solanum tuberosum suggests a role for carbonic anhydrase. Mol Plant-Microbe Interact. 2005; 18: 913-922. Ref.: https://goo.gl/DkK63s

19. Hoang CV, Chapman KD. Biochemical and molecular inhibition of plastidial carbonic anhydrase reduces the incorporation of acetate into lipids in cotton embryos and tobacco cell suspensions and leaves. Plant Physiol. 2002; 128: 1417-1427. Ref.: https://goo.gl/SlsBpl

20. Arasimowicz-Jelonek M, Kosmala A, Janus $\measuredangle$, Abramowski D, Floryszak-Wieczorek J. The proteome response of potato leaves to priming agents and S-nitrosoglutathione. Plant Sci. 2013; 198: 83-90. Ref.: https://goo.gl/MQAc2e

21. Janus $t$, Milczarek G, Arasimowicz-Jelonek M, Abramowski D, Billert $H$, et al. Normoergic NOdependent changes, triggered by a SAR inducer in potato, create more potent defense responses to Phytophthora infestans. Plant Sci. 2013; 211: 23-34. Ref.: https://goo.gl/Jv7QUE

22. Aamand R, Dalsgaard T, Jensen FB, Simonsen U, Roepstorff A, et al. Generation of nitric oxide from nitrite by carbonic anhydrase: a possible link between metabolic activity and vasodilation. Am J Physiol Heart Circ Physiol. 2009; 297: 2068-2074. Ref.: https://goo.gl/6roFif

23. Floryszak-Wieczorek J, Arasimowicz-Jelonek M, Abramowski D, Izbiańska K. Redox-sensing responses in the potato-Phytophthora infestans system. Oxidative stress and cell death in plants: Mechanisms and implications. Abstract book. 2013; 53.

24. James WC. An illustrated serioes of assesment keys for plant diseases, their preparation and usage. Can Plant Dis Surv. 1971; 51: 39-65. Ref.: https://goo.gl/nVAfHa

25. Floryszak-Wieczorek J, Arasimowicz-Jelonek M, Milczarek G, Janus $\measuredangle$, Pawlak-Sprada S, et al. Nitric oxide-mediated stress imprint in potato as an effect of exposure to a priming agent. Mol Plant Microbe Interact. 2012; 25: 1469-1477. Ref.: https://goo.gl/WfVylk

26. Floryszak-Wieczorek J, Arasimowicz M, Milczarek G, Jelen H, Jackowiak H. Only an early nitric oxide burst and the following wave of secondary nitric oxide generation enhanced effective defence responses of pelargonium to a necrotrophic pathogen. New Phytol. 2007; 175: 718-730. Ref.: https://goo.gl/klo5yH

27. Ciszewski A, Milczarek G. Electrochemical detection of nitric oxide using polymer modified electrodes. Talanta. 2003; 61: 11-26. Ref.: https://goo.gl/Keq3BI 
28. Li X, Hou J, Bai K, Yang X, Lin J, et al. Activity and distribution of carbonic anhydrase in leaf and ear parts of wheat (Triticum aestivum L.). Plant Sci. 2004; 166: 627-632. Ref.: https://goo.gl/fRkpvU

29. Chomcznski P, Sacchi N. Single-step method of RNA isolation by acid quanidinium thiocyanatephenol-chloroform extraction. Anal Biochem. 1987; 162: 156-159. Ref.: https://goo.gl/pPMqaM

30. Ye J, Coulouris G, Zaretskaya I, Cutcutache I, Rozen S, et al. Primer-BLAST: a tool to design target-specific primers for polymerase chain reaction. BMC Bioinformatics. 2012; 13: 134. Ref.: https://goo.gl/Ul4fKq

31. Zhao S, Fernald RD. Comprehensive algorithm for quantitative real-time polymerase chain reaction. J Comput Biol. 2005; 12: 1047-1064. Ref.: https://goo.gl/1pWkir

32. Pfaffl MW. A new mathematical model for relative quantification in real-time RT-PCR. Nucleic Acids Res. 2001; 29: e45. Ref.: https://goo.gl/m6yWxi

33. Freytag S, Arabatzis N, Hahlbrock K, Schmelzer E. Reversible cytoplasmic rearrangements precede wallapposition, hypersensitivecell death and defense-related geneactivation in potato/Phytophthora infestans interactions. Planta. 1994; 194: 123-135. Ref.: https://goo.gl/UnStrJ

34. Orłowska E, Fiil A, Kirk HG, Llorente B, Cvitanich C. Differential gene induction in resistant and susceptible potato cultivars at early stages of infection by Phytophthora infestans. Plant Cell Rep. 2012; 31: 187-203. Ref.: https://goo.gl/J5PgmE

35. Floryszak-Wieczorek J, Arasimowicz-Jelonek M. Contrasting regulation of NO and ROS in potato defense-associated metabolism in response to pathogens of different lifestyles. PLoS ONE. 2016; 11: e0163546. Ref.: https://goo.gl/mLeVGU

36. Schenk PM, Kazan K, Wilson I, Anderson JP, Richmond T, et al. Coordinated plant defense responses in Arabidopsis revealed by microarray analysis. Proc Natl Acad Sci U S A. 2000; 97: 11655-11660. Ref.: https://goo.gl/2EMtiO

37. Frick UB, Schaller A. cDNA micrarray analysis of fusicoccin-induced changes in gene expression in tomato plants. Planta. 2002; 216: 83-94. Ref.: https://goo.gl/ov4jDj

38. Polesani M, Desario F, Ferrarini A, Zamboni A, Pezzotti M, et al. cDNA-AFLP analysis of plant and pathogen genes expressed in grapevine infected with Plasmopara viticola. BMC Genomics. 2008; 9: 142. Ref.: https://goo.gl/bdtgfe

39. Leitner M, Vandelle E, Gaupels F, Bellin D, Delledonne M. NO signals in the haze: nitric oxide signalling in plant defence. Curr Opin Plant Biol. 2009; 12: 451-458. Ref.: https://goo.gl/NqKiJ4

40. Delledonne $M, X i a Y$, Dixon RA, Lamb C. Nitric oxide functions as a signal in plant disease resistance. Nature. 1998; 394: 585-588. Ref.: https://goo.gl/wLVmaL

41. Kolbert Z, Sahin N, Erdei L. Early nitric oxide (NO) responses to osmotic stress in pea, Arabidopsis and wheat. Acta Biol Szeged. 2008; 52: 63-65. Ref.: https://goo.gl/J5LxLN

42. Kolbert Z, Ortega L, Erdei L. Involvement of nitrate reductase (NR) in osmotic stress-induced NO generation of Arabidopsis thaliana L. roots. J Plant Physiol. 2010; 167: 77-80. Ref.: https://goo.gl/6XWvX1

43. Huang J, Bellin D, Chen J, Fontanesi K, Klainfelder Delledonne M. Novel pathway in formation of NO from nitrite uder normoxic conditions in Arabidopsis. $4^{\text {th }}$ Plant NO Club International Meeting. Edinburgh UK Book of Abstract. 2012.

44. Rumeau D, Cuine S, Fina L, Gault N, Nicole M, et al. Subcellular distribution of carbonic anhydrase in Solanum tuberosum L. leaves: Characterization of two compartment-specific isoforms. Planta. 1996; 199: 79-88. Ref.: https://goo.gl/QLY5nW

45. Winter $H$, Robinson DG, Heldt HW. Subcellular volumes and metabolite concentrations in spinach leaves. Planta. 1994; 193: 530-535. Ref.: https://goo.gl/YwISLv 